\title{
The Crystal and Molecular Structure of Thiuret Hydroiodide
}

\author{
OLAV FOSS and OLAV TJOMSLAND
}

Chemical Institute, University of Bergen, Bergen, Norway

\begin{abstract}
The crystal structure of the five-membered cyclic disulphide, thiuret hydroiodide, a 3,5-diamino derivative of 1,2,4-dithiazole, has been determined by two-dimensional X-ray methods. The disulphide group lies across a crystallographic mirror plane and is therefore planar, and the thiuret ion as a whole is planar or nearly so.

The crystals have four $\left[\mathrm{S}_{2}\left(\mathrm{C}-\mathrm{NH}_{2}\right)_{2} \mathrm{~N}\right] \mathrm{I}$ units in a cell based on

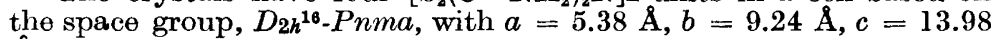
$\AA$. The dimensions of the thiuret ring were found to be, $\mathrm{S}-\mathrm{S}=2.09 \pm$ $0.012 \AA, \mathrm{S}-\mathrm{C}=1.73 \pm 0.03 \AA, \mathrm{C}-\mathrm{N}=1.31 \pm 0.03 \AA, \angle \mathrm{S}-\mathrm{S}-\mathrm{C}$ $=92.4 \pm 1^{\circ}, \angle \mathrm{S}-\mathrm{C}-\mathrm{N}=118 \pm 2^{\circ}, \angle \mathrm{C}-\mathrm{N}-\mathrm{C}=117 \pm 2^{\circ}$, and the exocyclic $\mathrm{C}-\mathrm{NH}_{2}$ bond, $1.36 \pm 0.03 \AA$. Within the experimental accuracy the carbon valencies are trigonal planar.
\end{abstract}

$\mathrm{T}$ hiourea reacts with numerous oxidizing agents to give salts of formamidinium disulphide, which according to recent crystal structure determinations of the diiodide and dibromide monohydrates ${ }^{1}$, contains a normal, nonplanar disulphide group. Similarly, the formal condensation product of two moles of thiourea, dithiobiuret, undergoes reversible oxidation by such reagents as hydrogen peroxide, iodine, ceric salts, thallic salts, or formamidinium disulphide salts, to give compounds which are regarded as salts of the base, thiuret, or 3,5-diimino-1,2,4-dithiazolidine ${ }^{2-5}$. This is a five-membered cyclic disulphide.

Fromm ${ }^{6}$ in 1893 first assigned the name, thiuret, and a disulphide formula, to an oxidation product of a dithiobiuret. Although a number of derivatives of dithiobiuret and thiuret were studied by Fromm and later workers ${ }^{5}$, the synthesis of dithiobiuret itself was not achieved until $1943^{7}$, and its oxidation product (thiuret hydrochloride and hydroiodide) described in $1947^{2,3}$. In this year, Preisler and Bateman ${ }^{2}$ published a potentiometric study of the reversible dithiobiuret-thiuret system:<smiles>NC(=S)NC(N)=S</smiles>

Acta Chem. Scand. 12 (1958) No. 9 
They found a value of $+0.25 \mathrm{~V}$ for the oxidation-reduction potential at $\mathrm{pH}=0$ and $30^{\circ} \mathrm{C}$, referred to the normal hydrogen electrode, as compared with $+0.42 \mathrm{~V}$ for the potential of the thiourea-formamidinium disulphide system measured earlier by Preisler and Berger ${ }^{8}$ :

$$
2\left(\mathrm{H}_{2} \mathrm{~N}\right)_{2} \mathrm{CS}=\left[\left(\mathrm{H}_{2} \mathrm{~N}\right)_{2} \mathrm{C}-\mathrm{S}-\mathrm{S}-\mathrm{C}\left(\mathrm{NH}_{2}\right)_{2}\right]+++2 \mathrm{O}
$$

Dithiobiuret is thus a markedly stronger reducing agent than thiourea. The acid dissociation constant of the monovalent thiuret cation was measured ${ }^{2}$ as $4 \times 10^{-8}$. The free thiuret base has not been isolated, the salts being rapidly decomposed by alkalies with elimination of sulphur.

A survey ${ }^{9}$ of unit cells and space groups of some 1,2,4-dithiazolidine derivatives, including thiuret hydrohalides, indicated the occurrence in the hydroiodide of a molecular mirror plane of symmetry and thereby of a planar cis disulphide group. This would be the first example of a planar disulphide group, all previous structure determinations of compounds of the type $\mathrm{X}-\mathrm{S}-\mathrm{S}-\mathrm{X}$ having given a dihedral angle XSS/SSX of about $90^{\circ}$. The barrier towards rotation about the $S-S$ bond, through the planar cis form with zero dihedral angle, has been estimated 10,11 as $10-14 \mathrm{kcal} / \mathrm{mole}$. A preliminary account of the crystal structure of the hydroiodide was published at the same time ${ }^{12}$.

\section{CRYSTAL DATA}

The salt was prepared by addition of an excess of aqueous potassium iodide to a warm aqueous solution of thiuret hydrochloride, and was recrystallized from water. The crystals are faintly yellow, m. p. (reported ${ }^{3}$ ) $247^{\circ} \mathrm{C}$. They occurred as prisms extended along the $a$ axis and bounded by $\{001\}$ and $\{011\}$. There is perfect cleavage along the $c$ plane, and a rather pronounced tendency of irregular growth and twinning, but crystals were found which gave satisfactory intensity photographs.

The crystals are orthorhombic, with the unit cell dimensions ${ }^{9}: a=5.38 \AA$, $b=9.24 \AA, c=13.98 \AA( \pm 0.5 \%)$. There are four $\left[\mathrm{S}_{2}\left(\mathrm{C}-\mathrm{NH}_{2}\right)_{2} \mathrm{~N}\right] \mathrm{I}$ units in the cell; density, calc. 2.50 , found $2.49 \mathrm{~g} / \mathrm{cm}^{3}$. From the systematic absences, $0 k l$ when $k+l$ is odd and $h k 0$ when $h$ is odd, and the subsequent structure analysis, the space group is $D_{2 h}{ }^{16}-P n m a$. The iodide ion and the ring nitrogen atom of the cation lie in the mirror plane of this space group, the other atoms are in general, eightfold positions. There are thus 13 positional parameters to be determined, excluding the hydrogen atoms.

\section{THE STRUCTURE ANALYSIS}

The intensities of the reflections of the three principal zones were estimated visually from zero-layer Weissenberg photographs. Copper radiation was used $\left(\mu=438 \mathrm{~cm}^{-1}\right)$ and crystals with cross-sections of $0.07 \times 0.07 \mathrm{~mm}$ for the $0 k l$ and $h k 0$ zones and $0.07 \times 0.03 \mathrm{~mm}$ for the $h 0 l$ zone. Out of $880 \mathrm{kl}$, $93 h 0 l$ and $33 h k 0$ reflections within the range $\sin \Theta<0.985,83,86$ and 29 , respectively, were observed and measured. The intensities were corrected for the Lorenz and polarization factors in the usual way, but not for absorp- 


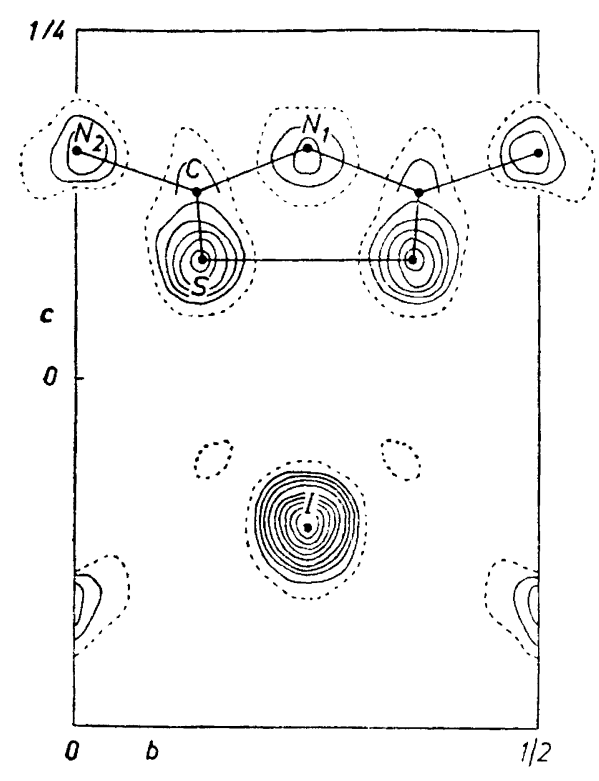

Fig. 1. Electron density projection of thiuret hydroiodide along the $a$ axis. Contours at intervals of $10 \mathrm{e} \cdot \AA^{-2}$ for iodine, 4 e $\cdot \AA^{-2}$ for sulphur, 2 e $\cdot \AA^{-2}$ for carbon and nitrogen, beginning with 4 e. $\AA^{-2}$ (dashed). The mirror plane is normal to the plane of the paper and passes through $\mathrm{I}$ and $\mathrm{N}_{1}$.

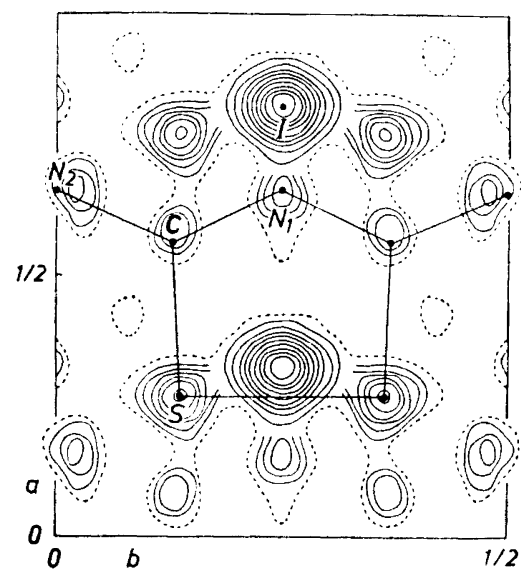

Fig. 2. Electron density projection of thiuret hydroiodide along the $c$ axis. The contour interval is $3 \mathrm{e} \cdot \AA^{-2}$ for carbon and nitrogen, and the 8-electron line is dashed; otherwise as in Fig. 1.

tion, and were converted to relative structure amplitudes and ultimately brought to an approximately absolute scale by comparison with the calculated values.

The coordinates of the iodide ion were found from Patterson projections, and the structure was solved by use of the heavy atom method and refined through successive Fourier and Fourier difference syntheses. Summations were made by means of Beevers-Lipson strips, at $12^{\circ}$ intervals along the $a$ axis and $6^{\circ}$ intervals along the $b$ and $c$ axes. The $0 k l$ zone was refined first, and the $h 0 l$ zone next considered, but here extensive overlapping occurred, so that attention was shifted to the $h k 0$ zone. The five $x$ coordinates are thus based on the 29 observed $h k 0$ reflections; together with the five thermal parameters employed for this zone the number of variables is fairly large relative to the number of observations.

The $0 k l$ and $h k 0$ electron density maps are shown in Figs. 1 and 2, and the final atomic coordinates are listed in Table 1. The positions corresponding to these coordinates are marked with dots in Figs. 1 and 2 . It is seen that particularly in the $h k 0$ projection the maxima of the electron density peaks differ markedly from the final positions, apparently because of series termination effects corrected for through the difference refinement.

Acta Chem. Scand. 12 (1958) No. 9 
Table 1. Atomic coordinates for thiuret hydroiodide, in fractions of cell edges. Origin at a centre of symmetry.

$x$

$\begin{array}{ll}\mathrm{I} & 0.8235 \\ \mathrm{~N}_{1} & 0.665 \\ \mathrm{~S} & 0.270 \\ \mathrm{C} & 0.565 \\ \mathrm{~N}_{2} & 0.662\end{array}$

\begin{tabular}{ll}
$y$ & \multicolumn{1}{c}{$z$} \\
0.250 & -0.1075 \\
0.250 & 0.165 \\
0.1370 & 0.0845 \\
0.129 & 0.134 \\
0.000 & 0.163
\end{tabular}

The observed and calculated values of the $0 k l$ and $h k 0$ structure factors are listed in Table 2. The calculated values are based on the atomic scattering curves of Berghuis et al. ${ }^{13}$ for carbon and nitrogen, of Viervoll and Ögrim ${ }^{14}$ for sulphur, and an iodine curve constructed from the Thomas-Fermi values for xenon at small scattering angles and electroneutral iodine at intermediate and large angles. In the temperature factor $\exp \left[-B\left(\sin ^{2} \Theta / \lambda^{2}\right)\right]$ the following values of $B$ were finally adopted, mainly on the basis of the difference maps: In the $0 k l$ zone, $B=\left(2.3+0.8 \cos ^{2} \varphi\right) \AA^{2}$ for iodine, where $\varphi$ is the angle between the normal of the reflecting plane and the $c$ axis, and $B=2.6 \AA$ for the other atoms. In the $h k 0$ zone, $B=\left(2.0+0.5 \cos ^{2} \varphi\right) \AA^{2}$ for iodine and $\left(1.8+0.8 \cos ^{2} \varphi\right) \AA^{2}$ for sulphur, where $\varphi$ is the angle between the normal of the reflecting plane and the $b$ axis, and $B=2.3 \AA^{2}$ for carbon and nitrogen. No significance in terms of anisotropic thermal vibrations should be attached to the $B$ values, as they may reflect absorption and other errors in the observed structure factors.

In the case of the $\mathrm{C}$ and $\mathrm{N}_{2}$ atoms the $y$ coordinates used for the final structure factor calculations were, $y(\mathrm{C})=0.126$ and $0.132, y\left(\mathrm{~N}_{2}\right)=-0.002$ and +0.002 , respectively, for the $0 k l$ and $h k 0$ zones. The values of Table 1 are weighted means.

The reliability index, $R=\Sigma|| F_{\mathrm{o}}|-| \boldsymbol{F}_{\mathrm{c}}|| \Sigma\left|\boldsymbol{F}_{\mathrm{o}}\right|$, with non-observed reflections included when $\left|F_{c}\right|$ is larger than the observable limit, is 0.073 for the $0 k l$ zone and 0.061 for the $h k 0$ zone. The strong reflections 004 and 033 have calculated values relatively much larger than the observed ones, and were omitted from the calculation of $R$ index and scale factors for the zone, and from the difference syntheses. A calculation of structure factors for the $h 0 l$ zone, using the $x$ and $z$ coordinates derived from the $0 k l$ and $h k 0$ zones and an approximate temperature correction with $B=4.0 \AA^{2}$, gave a $R$ index of 0.15 for this zone.

\section{ASSESSMENT OF ACCURACY}

The standard deviation of electron density, evaluated from the difference maps, is $0.7 \mathrm{e} . \AA^{-2}$ for the $0 k l$ zone and $1.2 \mathrm{e} . \AA^{-2}$ for the $h k 0$ zone. The s.d. of the atomic coordinates were estimated from the root-mean-square of the gradients in the difference maps and the curvatures of the electron density peaks ${ }^{15,16}$, and the following values were found: $\sigma(x)=0.003 \AA, \sigma(z)=0.002$ $\AA$ for iodine, $\sigma(x)=0.010 \AA, \sigma(y)=0.006 \AA, \sigma(z)=0.009 \AA$ for sulphur, and $\sigma=0.02 \AA$ for the carbon and nitrogen coordinates, except $\sigma(z)$ for carbon 
Table 2. Observed and calculated $0 k l$ and $h k 0$ structure factors for thiuret hydroiodide.

\begin{tabular}{|c|c|c|c|c|c|c|c|c|}
\hline$l$ & $F_{\mathrm{o}}$ & $F_{\mathrm{c}}$ & $l$ & $F_{\mathrm{o}}$ & $F_{\mathrm{c}}$ & $l$ & $F_{\mathrm{o}}$ & $F_{\mathrm{c}}$ \\
\hline & $\begin{array}{c}\text { Okl zon } \\
00 \mathrm{l}\end{array}$ & & & $\begin{array}{r}04 l \\
57\end{array}$ & & & $0,10, l$ & \\
\hline 2 & 53 & +57 & $\begin{array}{l}14 \\
16\end{array}$ & $\begin{array}{l}57 \\
15\end{array}$ & $\begin{array}{r}-60 \\
-\quad 3\end{array}$ & 4 & $\begin{array}{l}21 \\
51\end{array}$ & $\begin{array}{r}21 \\
+\quad 51\end{array}$ \\
\hline 4 & 244 & -275 & & & & $\begin{array}{l}\mathbf{4} \\
6\end{array}$ & $\begin{array}{l}01 \\
43\end{array}$ & $\begin{array}{r}+41 \\
+\quad 44\end{array}$ \\
\hline 6 & 100 & -103 & & $05 l$ & & 8 & 17 & -20 \\
\hline 8 & 48 & +46 & 1 & 112 & -108 & & & \\
\hline 10 & 83 & +82 & 3 & 156 & -165 & & $0,11, l$ & \\
\hline 12 & 31 & +30 & 5 & 8 & +5 & 1 & 25 & +26 \\
\hline 14 & 32 & -35 & 7 & 134 & +121 & 3 & 33 & +38 \\
\hline \multirow[t]{2}{*}{16} & 21 & -24 & 9 & 46 & +43 & 5 & 9 & -9 \\
\hline & $01 l$ & & $\begin{array}{l}11 \\
13\end{array}$ & $\begin{array}{l}46 \\
35\end{array}$ & $\begin{array}{l}-45 \\
-\quad 34\end{array}$ & & & \\
\hline 1 & 34 & -37 & 15 & $<6$ & $\begin{array}{r}4 \\
+\quad 4\end{array}$ & $k$ & $0 k j$ & \\
\hline 3 & 70 & -76 & & & & 2 & 179 & -186 \\
\hline 5 & 31 & +32 & & $06 l$ & & 4 & 108 & +103 \\
\hline 7 & 111 & +107 & 0 & 78 & -77 & 6 & 81 & -71 \\
\hline 9 & $<8$ & -8 & 2 & 18 & -16 & 8 & 131 & +131 \\
\hline 11 & 90 & -89 & 4 & 80 & +72 & 10 & 67 & -67 \\
\hline 13 & 22 & -23 & 6 & 45 & +41 & & & \\
\hline 15 & 39 & +48 & 8 & 63 & -54 & & $2 k 0$ & \\
\hline \multirow[t]{3}{*}{17} & 22 & +33 & 10 & 54 & -48 & 0 & 197 & -182 \\
\hline & & & 12 & 25 & +26 & 1 & 104 & +113 \\
\hline & $02 l$ & & 14 & 37 & +39 & 2 & 92 & +94 \\
\hline 0 & 172 & -183 & & & & 3 & 98 & -100 \\
\hline 2 & 55 & -57 & & $07 l$ & & 4 & 45 & -47 \\
\hline 4 & 127 & +141 & 1 & 44 & +39 & 5 & 73 & +73 \\
\hline 6 & 104 & +106 & 3 & 70 & +63 & 6 & 30 & +36 \\
\hline 8 & 70 & -67 & 5 & 12 & -11 & 7 & 60 & -57 \\
\hline 10 & 87 & -85 & 7 & 74 & -67 & 8 & 65 & -68 \\
\hline 12 & 13 & +16 & 9 & 10 & -10 & 9 & 45 & +42 \\
\hline 14 & 43 & +46 & 11 & 47 & +48 & 10 & 41 & +39 \\
\hline \multirow[t]{2}{*}{16} & $<6$ & +6 & 13 & 17 & +20 & 11 & 26 & -29 \\
\hline & $03 l$ & & & $08 l$ & & & $4 k 0$ & \\
\hline l & 115 & +127 & 0 & 130 & +132 & 0 & $<9$ & $+\quad \mathbf{3}$ \\
\hline 3 & 167 & +191 & 2 & 23 & +22 & 1 & 130 & -114 \\
\hline 5 & 16 & -16 & 4 & 96 & -95 & 2 & 14 & +15 \\
\hline 7 & 137 & -140 & 6 & 51 & -48 & 3 & 62 & +61 \\
\hline 9 & 38 & -35 & 8 & 25 & +25 & 4 & 67 & \\
\hline 11 & 66 & +61 & 10 & 39 & +41 & 5 & 36 & -41 \\
\hline 13 & 37 & +33 & 12 & 10 & +11 & 6 & 23 & +27 \\
\hline 15 & 8 & $-\quad 13$ & & & & 7 & 50 & +58 \\
\hline \multirow[t]{3}{*}{17} & 13 & -17 & & $09 l$ & & 8 & $<8$ & $-\quad 1$ \\
\hline & & & $\mathbf{l}$ & 14 & -18 & 9 & 44 & -50 \\
\hline & $04 l$ & & 3 & 22 & -23 & & & \\
\hline 0 & 100 & +102 & 5 & 14 & +19 & & $6 k 0$ & \\
\hline 2 & 24 & -18 & 7 & 35 & +37 & 0 & 36 & +36 \\
\hline 4 & 90 & -88 & 9 & 13 & -10 & 1 & 30 & +32 \\
\hline 6 & 17 & +8 & 11 & 35 & -40 & 2 & 46 & -42 \\
\hline 8 & 69 & +61 & & & & 3 & $<7$ & -11 \\
\hline 10 & 49 & +39 & & $0,10, l$ & & 4 & 76 & +74 \\
\hline 12 & 27 & -26 & 0 & 65 & -67 & 5 & $<5$ & +4 \\
\hline
\end{tabular}




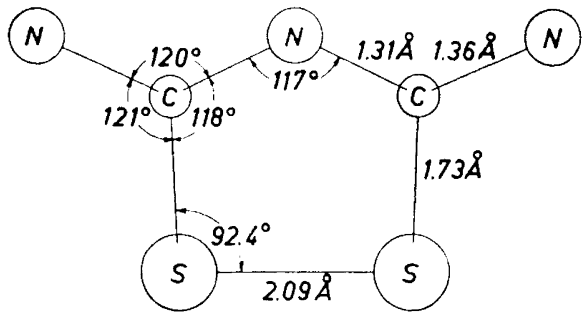

Fig. 3. The thiuret ion, with bond lengths and angles.

which is larger because of overlapping. $y$ for iodine and $N_{1}$ are fixed by symmetry relations. This gives $\sigma=0.012 \AA$ for the $S-S$ bond length across the mirror plane, about $0.03 \AA$ for $\mathrm{S}-\mathrm{C}$ and $\mathrm{C}-\mathrm{N}$ bond lengths, $\mathrm{I}^{\circ}$ for the $\mathrm{S}-\mathrm{S}-\mathrm{C}$ angle and $2^{\circ}$ for other bond angles in the cation.

\section{THE THIURET ION}

The bond lengths, as calculated from the atomic coordinates of Table 1, are as follows: $\mathrm{S}-\mathrm{S}=2.088 \AA, \mathrm{S}-\mathrm{C}=1.73 \AA, \mathrm{C}-\mathrm{N}_{1}$ (cyclic) $=1.31 \AA$, $\mathrm{C}-\mathrm{N}_{2}$ (exocyclic) $=1.36 \AA$, and the angles, $\mathrm{S}-\mathrm{S}-\mathrm{C}=92.4^{\circ}, \mathrm{S}-\mathrm{C}-\mathrm{N}_{1}$ $=118.1^{\circ}, \mathrm{C}-\mathrm{N}_{1}-\mathrm{C}=116.9^{\circ}, \mathrm{N}_{2}-\mathrm{C}-\mathrm{S}=120.5^{\circ}, \quad \mathrm{N}_{2}-\mathrm{C}-\mathrm{N}_{1}=119.5^{\circ}$. The cation as seen in projection along the $c$ crystal axis is shown in Fig. 3 .

The $S-S$ bond appears to be significantly longer than $2.04-2.05 \AA$ normally found in non-cyclic disulphides, e.g., $2.044 \pm 0.01 \AA$ in formamidinium disulphide dibromide monohydrate ${ }^{1}$. Within the accuracy of the results the carbon valencies are trigonal planar, and although the rather large s.d. do not permit definite conclusions, the found lengths for the three bonds from carbon indicate that they possess some double-bond character. If the lengths of single and double bonds between the atoms in the appropriate hybridization states are taken to be ${ }^{17-19}, \mathrm{C}-\mathrm{N}=1.47 \AA, \mathrm{C}=\mathrm{N}=1.27 \AA, \mathrm{C}-\mathrm{S}=1.80$ $\AA, \mathrm{C}=\mathrm{S}=1.60 \AA$, Pauling's expression relating bond length and bond order 20 gives about $55 \%$ double-bond character for the $\mathrm{C}-\mathrm{N}_{1}$ bond, $30 \%$ for the $\mathrm{C}-\mathrm{N}_{2}$ bond and $15 \%$ for the $\mathrm{C}-\mathrm{S}$ bond. Although to discuss bond orders when the experimental uncertainty is $0.03 \AA$ seems rather naive, the results are reasonable.

The shortness of the ring $\mathrm{C}-\mathrm{N}$ bond thus indicates that the ring $\mathrm{N}_{1}$ atom has a $\pi$ orbital available for overlap with the carbon $\pi$ orbital. Since mirror plane symmetry of the thiuret ion is crystallographically required, it follows that of the four hydrogen atoms of the ion, two are bonded to each of the exocyclic $\mathrm{N}_{2}$ nitrogen atoms. The other mirror plane-symmetric alternative, one hydrogen atom on each $\mathrm{N}_{2}$ atom and two on the ring $\mathrm{N}_{1}$ atom, would make $\mathrm{N}_{1}$ quaternary and leave no available $\pi$ orbital. The $\mathrm{C}-\mathrm{N}_{1}$ bond should then be expected to be considerably longer than the $\mathrm{C}-\mathrm{N}_{2}$ bond, and the $\mathrm{C}-\mathrm{N}_{1}-\mathrm{C}$ angle should be closer to tetrahedral. The found value for the angle $\left(117^{\circ}\right)$ is in agreement with the observation ${ }^{21,22}$ that in heterocyclic rings containing nitrogen atoms, the bond angle of the (mainly $s p^{2}$-hybridized) nitrogen is less than $120^{\circ}$. A diamino as contrasted with a diimino structure 
should correspond to higher stability as a result of conjugation across the ring nitrogen atom, of the two $s p^{2}$-hybridized carbon atoms. A similar nitrogen bridge between carbon atoms each bonded to an amino group occurs in melamine, 2,4,6-triamino-s-triazine ${ }^{23}$.

The $\mathrm{N}_{2}-\mathrm{C}-\mathrm{N}_{1}-\mathrm{C}-\mathrm{N}_{2}$ grouping is planar. A least-squares plane through the atoms:

$$
0.6209 X-0.7839 Z=0.419
$$

( $X$ and $Z$ in $\AA$ ) passes through $\mathrm{C}$ and at $-0.006 \AA$ from $\mathrm{N}_{1}$ and $+0.006 \AA$ from $\mathrm{N}_{2}$. This plane makes an angle of $15^{\circ}$ with the $\mathrm{C}-\mathrm{S}-\mathrm{S}-\mathrm{C}$ plane. A least-squares plane through all the atoms of the cation, with the sulphur coordinates given three times the weight of the carbon and nitrogen coordinates:

$$
0.4544 X-0.8908 Z=-0.384
$$

passes at a shortest distance of $-0.008 \AA$ from $S,+0.097 \AA$ from $\mathrm{C},-0.046$ $\AA$ from $\mathrm{N}_{1}$ and $-0.027 \AA$ from $\mathrm{N}_{2}$. The distances are particularly dependent on the $z$ coordinates, and since the $z$ coordinate of $\mathrm{C}$ probably has a larger s.d. than the other light atom coordinates $(0.02 \AA)$ the apparent deviation from planarity of the thiuret ion as a whole can hardly be considered significant. However, distortions from planarity do sometimes occur in crystals of molecules which on the basis of hybridization and resonance considerations should be expected to be planar ${ }^{17,24}$.

The thiuret ion contains two thiourea groups, and is formally derived from the formamidinium disulphide ion through ring closure under elimination of an ammonium ion. Neither in the structure analyses of formamidinium disulphide diiodide and dibromide monohydrates ${ }^{1}$ do the experimental results permit a decision whether the thiourea groups are quite planar or not. The difference between the $\mathrm{C}-\mathrm{S}$ bond lengths in the dibromide ${ }^{1}(1.78 \AA)$ and in thiuret hydroiodide $(1.73 \AA)$ is within the limits of error. Thiourea itself is planar in the crystals ${ }^{25}$, with $\mathrm{C}-\mathrm{S}=1.71 \pm 0.01 \AA$.

\section{THE PLANARITY OF THE DISULPHIDE GROUP}

The disulphide group lies across a crystallographic mirror plane. Therefore, unless the mirror plane symmetry is statistical, the disulphide group is exactly planar. Such groups are normally non-planar, with a dihedral angle of about $90^{\circ}$ between the planes of the valencies of the two sulphur atoms ${ }^{19}$, there being a barrier of $10-14 \mathrm{kcal} / \mathrm{mole}^{10,11}$ towards rotation about the $\mathrm{S}-\mathrm{S}$ bond, through the planar cis and trans forms. This barrier can be explained ${ }^{26,27}$ as arising principally from the mutual repulsion of the unshared $p \pi$ electron pairs, one on each sulphur atom. The $\sigma$-bonding orbitals of sulphur are thereby assumed to be nearly pure $p$ in character. The possibility exists that extra stability is conferred upon the $S-S$ bond in the non-planar form with about $90^{\circ}$ dihedral angle, through overlap of the sulphur $p \pi$ electron pair with an available $d$ orbital of the bond partner; the $S-S$ bond would then have some $p d \pi$-bond character. The $\mathrm{S}-\mathrm{S}$ bond of about $2.04 \AA$ in non-cyclic 
disulphides and the short bonds of the same length in the tetra- and pentathionate ions would, on the basis of the present knowledge about length-order relations for $\mathrm{S}-\mathrm{S}$ bonds ${ }^{\mathbf{1 9}, 28}$, correspond to about $20 \% \pi$-bonding.

In the relatively stable thiuret hydroiodide, with planar disulphide group, the $\mathrm{S}-\mathrm{S}$ rotation barrier, if it exists also there, must be compensated through other effects, such as favourable lattice conditions in the mirror-plane arrangement, and through resonance stabilization of the ring. The most probable resonance forms of the supposedly correct tautomer of the thiuret ion are<smiles></smiles>

(A)<smiles></smiles>

(B)

and their mirror images. Form A would seem to be the more important one, and confer considerable stability on the ion. Form B involves a $\pi$ electron pair of sulphur.

The incorporation of the disulphide group in a five-membered ring will, for strain reasons, not allow a normal dihedral angle of about $90^{\circ}$; however, in the saturated five-membered cyclic disulphide, 1,2-dithiolane-4-carboxylic acid ${ }^{29,30}$, the dihedral angle is not zero but $27 \pm 1^{\circ}$, and the dithiolane ring is rather unstable. It appears that the unsaturated character of the thiuret ring system is responsible for the planarity of the disulphide group and the stability of the ion. The presence of an unsaturated carbon atom ( $s p^{2}$-hybridized, with an available $p \pi$ orbital) adjacent to each sulphur atom is not a sufficient requisite for planarity of a disulphide group; in the non-cyclic formamidinium disulphide ion, where the carbon atoms are in the same state of hybridization as in the thiuret ion and also there bonded to a sulphur and two nitrogen atoms, the disulphide group is non-planar, with a dihedral angle of $105^{\circ}$ in the diiodide and $89^{\circ}$ in the dibromide ${ }^{1}$. The question arises whether the planarity of the disulphide group in unsaturated cyclic disulphides of the thiuret type is due in some degree to $\pi$-electron conjugation over the ring as a whole, with participation of sulphur $\pi$ orbitals; in cyclic conjugated systems such as thiophen and thiazole, a sulphur atom replaces a $-\mathrm{CH}=\mathrm{CH}-$ group and contributes two $\pi$ electrons to the aromatic sextet. From the observed $\mathbf{S}-\mathrm{S}$ bond length in thiuret hydroiodide, conjugation across the $\mathbf{S}-\mathbf{S}$ bond does not appear to be very strong. In a crystal structure analysis of another unsaturated five-membered cyclic disulphide, 4-methyl-1,2-dithia-4cyclopentene-3-thione, Kehl and Jeffrey ${ }^{31}$ have found that the molecule lies approximately in a plane. They state that "From the observed bond lengths the five-membered ring has some aromatic character. - This $\pi$-bonding does not, however, appear to include the $\mathrm{S}_{1}-\mathrm{S}_{2}$ link, which has a normal single bond length (2.03 $\AA$ )." The bond is thus shorter than the S-S bond in thiuret hydroiodide; on the basis of the available length-order data ${ }^{19,28}$ the length does indicate $20-30 \% \pi$ character. It is noteworthy that the ring atoms in the thiuret ion have a sextet of $\pi$ electrons, as have the ring atoms in the tri- 


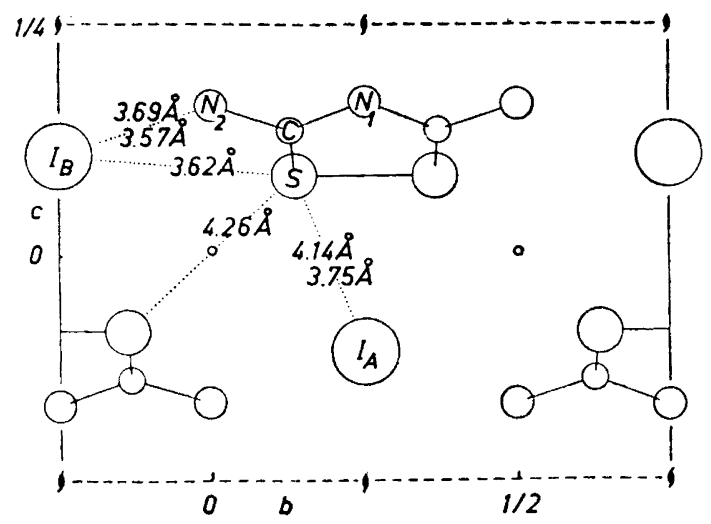

Fig. 4. The ionic arrangement as seen along the $a$ axis. Half a unit cell is shown.

thiones of which the above 4-methyl derivative is an example. Lüttringhaus $\mathbf{3 2 , 3 3}^{\mathbf{3}}$ has emphasized the aromatic, thiophen-like character of the trithione ring in the thiocarbonyl polarized form, and pointed out that in this ring system the planar form of the disulphide group appears to be stable.

\section{THE IONICENVIRONMENT}

The arrangement of thiuret ions and iodide ions as seen along the $a$ crystal axis is shown in Fig. 4.

The crystals have a layer structure, there being no bonds and only weak non-bonded contacts across the glide plane $a$ normal to the $c$ axis at $z=\frac{1}{4}$ and $-\frac{1}{4}$. This accounts for the perfect cleavage along the $c$ plane. The shortest distances across the glide plane are, $\mathrm{N}_{1}-\mathrm{N}_{1}=3.55 \AA, \mathrm{N}_{2}-\mathrm{N}_{2}=3.63 \AA$, $\mathrm{N}_{2}-\mathrm{N}_{1}=4.30$ and $4.31 \AA, \mathrm{N}_{2}-\mathrm{I}=3.95 \AA$ and $\mathrm{I}-\mathrm{I}=4.81 \AA$. The $\mathrm{N}-\mathrm{N}$ approaches are not close enough for van der Waals contacts or hydrogen bonds between the atoms, and the I-I distance is longer than twice the ionic radius of iodine, $2.16 \AA^{20}$. If the hydrogen atoms are trigonally bonded to $\mathrm{N}_{2}$ and lie in or not too far removed from the least-squares plane of the thiuret ion, then one of the $\mathrm{N}_{2}-\mathrm{H}$ bonds is directed approximately toward the related nitrogen atom $\left(\mathrm{N}_{2}{ }^{\prime}\right)$ across the glide plane, at an angle of about $60^{\circ}$ with the plane of the thiuret ion to which $\mathrm{N}_{2}^{\prime}$ belongs. $\mathrm{N}_{2}{ }^{\prime}$ lies $15^{\circ}$ out of the plane of the first thiuret ion, as seen from $\mathrm{N}_{2}$, and the $\mathrm{C}-\mathrm{N}_{2}-\mathrm{N}_{2}^{\prime}$ angle is $119^{\circ}$. With a $\mathrm{N}-\mathrm{H}$ bond length of $1.0 \AA$ and van der Waals radii for hydrogen and nitrogen of 1.2 and $1.5 \AA$, respectively ${ }^{20}$, the $\mathrm{N}_{2}-\mathrm{N}_{2}^{\prime}$ distance of $3.63 \AA$ may indicate a weak contact between hydrogen and $\mathrm{N}_{2}{ }^{\prime}$.

There are several close non-bonded approaches within a layer. In Fig. 4, the iodide ion $I_{B}$ is related to $I_{A}$ through the symmetry centre in $\frac{1}{2}, 0,0$; the coordinates of $\mathrm{I}_{\mathrm{A}}$ are those listed in Table 1. $\mathrm{N}_{2}$ lies $3.57 \AA$ from $\mathrm{I}_{\mathrm{B}}$ and 3.69 $\AA$ from $\mathrm{I}_{\mathrm{B}(\mathbf{1 0 0 )})}$; these iodide ions are $-0.52 \AA$ and $+1.92 \AA$, respectively, out of the plane of the thiuret ion. A trigonal $\mathrm{N}_{2}-\mathrm{H}$ bond located in this plane 
would be directed about $20^{\circ}$ away from $I_{B}$, as seen from $N_{2}$, and the hydrogen atom would lie about $2.8 \AA$ from $\mathrm{I}_{\mathrm{B}}$.

Each sulphur atom forms close contacts with two iodide ions and a weaker one with a third. If the coordinates of the reference sulphur atom are those listed in Table 1 , the contacts are $\mathrm{S}-\mathrm{I}_{\mathrm{A}}=4.14 \AA, \mathrm{S}-\mathrm{I}_{\mathrm{A}\left(\mathbf{T}_{00}\right)}=3.75 \AA$ and $\mathrm{S}-\mathrm{I}_{\mathrm{B}}=3.62 \AA$. In formamidinium disulphide diiodide monohydrate ${ }^{1}$ the closest $\mathrm{S}-\mathrm{I}$ approaches are 3.91 and $3.95 \AA$, and in $2,2^{\prime}$-diiododiethyltrisulphide ${ }^{34}$, with covalent iodine, $3.74,3.80$ and $3.85 \AA$. It appears that the value, $1.60 \AA$ proposed by Donohue ${ }^{34}$ for the van der Waals radius of sulphur fits the experimental data, at least for $\mathrm{S}-\mathrm{I}$ contacts, better than does the Pauling value ${ }^{20}$ of $1.85 \AA$.

The environment of an iodide ion is as follows. Located in a mirror plane, it has on each side of the plane two nitrogen atoms at 3.57 and $3.69 \AA$ and three sulphur atoms at $3.62,3.75$ and $4.14 \AA$, and in the plane a nitrogen atom at $3.90 \AA$; these approaches are all within the layer. In the adjacent layer there is a nitrogen atom at $3.95 \AA$ on each side of the mirror plane, and two iodide ions in the plane, both at $4.81 \AA$.

The shortest non-bonded $\mathrm{S}-\mathrm{S}$ distance in the crystals is $4.26 \AA$ over a centre of symmetry.

The work has been supported financially by Norges Almenvitenskapelige Forskningsråd. A sample of thiuret hydrochloride was generously provided by American Cyanamid Company, New York.

\section{REFERENCES}

1. Foss, O., Johnsen, J. and Tvedten, O. Acta Chem. Scand. 12 (1958) 1782.

2. Preisler, P. W. and Bateman, M. M. J. Am. Chem. Soc. 69 (1947) 2632.

3. American Cyanamid Co. Dithiobiuret, Technical Data Sheet, New York, 1947.

4. American Cyanamid Co. New Product Bulletin, Collective Vol. I, Now York 1952 p. 54.

5. Kurzer, F. Chem. Revs. 56 (1956) 95.

6. Fromm, E. Ann. 275 (1893) 20.

7. Sperry, R. L. U. S. patent 2371 112; Chem. Abstracts 39 (1945) 3556.

8. Preisler, P. W. and Berger, L. J. Am. Chem. Soc. 69 (1947) 322.

9. Foss, O. Acta Chem. Scand. 10 (1956) 868.

10. Scott, D. W., Finke, H. L., Gross, M. E., Guthrie, G. B. and Huffman, H. M. J. Am. Chem. Soc. 72 (1950) 2424.

11. Scott, D. W., Finke, H. L., McCullough, J. P., Gross, M. E., Pennington, R. E. and Waddington, G. J. Am. Chem. Soc. 74 (1952) 2478.

12. Foss, O. and Tjomsland, O. Acta Chem. Scand. 10 (1956) 869.

13. Berghuis, J., Haanappel, I. M., Potters, M., Loopstra, B. O., MacGillavry, C. H. and Veenendaal, A. L. Acta Cryst. 8 (1955) 478.

14. Viervoll, H. and Ögrim, O. Acta Cryst. 2 (1949) 277.

15. Cruickshank, D. W. Acta Cryst. 2 (1949) 65.

16. Cochran, W. Acta Cryst. 4 (1951) 81.

17. Wheatley, P. J. Acta Cryst. 6 (1953) 369.

18. Donohue, J., Lavine, L. R. and Rollett, J. S. Acta Cryst. 9 (1956) 655.

19. Abrahams, S. C. Quart. Revs. London 10 (1956) 407.

20. Pauling, L. The Nature of the Chemical Bond, Cornell University Press, Ithaca, N. Y. 1945.

21. Bertinotti, F., Giacomello, G. and Liquori, A. M. Acta Cryst. 9 (1956) 510.

22. Wheatley, P. J. Acta Cryst. 10 (1957) 182.

23. Hughes, E. W. J. Am. Chem. Soc. 63 (1941) 1737. 
24. Wheatley, P. J. Ann. Rev. Phys. Chem. 8 (1957) 373.

25. Truter, M. R. Acta Cryst. 10 (1957) 785.

26. Pauling, L. Proc. Natl. Acad. Sci. U. S. 35 (1949) 495.

27. Bergson, G. Arkiv Kemi 12 (1958) No. 24.

28. Foss, O. and Tjomsland, O. Acta Chem. Scand. 12 (1958) 44.

29. Foss, O. and Tjomsland, O. Acta Chem. Scand. 11 (1957) 1426.

30. Bergson, G. and Schotte, L. Acta Chem. Scand. 12 (1958) 367.

31. Kehl, W. L. and Jeffrey, G. A. Acta Cryst. 10 (1957) 807.

32. Lüttringhaus, A. Angew. Chem. 59 (1947) 244.

33. Lüttringhaus, A. and Hägele, K. Angew. Chem. 67 (1955) 304.

34. Donohue, J. J. Am. Chem. Soc. 72 (1950) 2701.

Received August 12, 1958. 